\title{
Nasal and Paranasal Sinuses of the Donkey: Gross anatomy and Computed Tomography
}

\author{
El-Gendy,S.A. and Alsafy, M.A.M \\ Anatomy and Embryology Department, Faculty of Veterinary Medicine, Alexandria Uni- \\ versity, Edfina, Rashed, Behera, Egypt \\ E-mail: elgendyanatomist@yahoo.com
}

With 5 figures

Received in Marsh, accepted for publication in April, 2010

\begin{abstract}
The current work aimed to describe the anatomical findings of the nasal and paranasal sinuses of the donkey by gross anatomical observation of the skull and cadaver head through crosssections, sagittal sections and computed tomography (CT) imaging. Seven adult donkeys and ten skulls were used in this study. The donkey head had six pairs of sinuses, three paranasal; the frontal, maxillary and sphenopalatine sinuses and three nasal; dorsal, middle and ventral conchal sinuses. The left and right frontal sinuses were completely divided by a thick bony septum. Each frontal sinus is united rostrally with the dorsal conchal sinus forming conchofrontal sinus that communicated directly with the caudal maxillary sinus by frontomaxillary opening. The maxillary sinus is divided into rostral and caudal compartments by a thin incomplete bony septum. The caudal maxillary sinus is divided into medial and lateral compartments by the infraorbital canal that run longitudinally through it. The rostral maxillary sinus is communicated with the ventral conchal sinus through the conchomaxillary opening, while the rostral and caudal maxillary sinuses are connected with the middle nasal meatus via the slit-like nasomaxillary opening. Approach to the interior of the frontal,
\end{abstract}

rostral and caudal maxillary was determined. The location, size, and shape of the paranasal sinuses openings (conchomaxillary, nasomaxillary, frontomaxillary and sphenopalatinal openings and opening of middle conchal sinus into caudal maxillary sinus) communicated the sinuses with the nasal cavity were identified in CT. The frontomaxillary opening was the largest opening, while the nasomaxillary opening was the narrowest one. CT images with crosssections provided clear, unobstructed images on the paranasal structures, while paranasal lining was unclear in CT images because of its thin layer.

\section{Keywords}

Nasal, Paranasal sinuses, Gross Anatomy; CT scans; cross-sections, Donkey.

\section{Introduction}

Donkeys belong to the family Equidae and are similar to equines in many ways. However, there are a number of significant features peculiar to the donkey that practitioners should be aware when attempting to investigate and treat respiratory diseases. These include differences in anatomy, physiology, pharmacokinetics, disease incidence 
and morbidity with certain infectious diseases. Worldwide there are an estimated 44 million donkeys. Of these $96 \%$ are found in the developing countries contributing significantly to the rural economy. While in Europe and in U.S.A. the absolute numbers of donkeys are declining, their importance as companion animals is increasing. Thus, there is a need for equine practitioners to treat donkey patients in an informed and sensitive manner (Starkey 1997, Thiemann and Bell 2001).

Computed tomography of the equine head is an established imaging technique that is becoming more commonly performed in most institutional and private hospitals which incorporating CT units into their diagnostic services (Solano and Brawer 2004). The major advantage of CT over conventional radiographs is lack of superimposition and enhanced demonstration of individual components of the skull. In addition, the regions of interest have high inherent radiographic contrast and $\mathrm{CT}$ provides clear, unobstructed images (Barbee et al., 1987 and Gibbs, 1999).

In addition, computed tomography of the equine head is the ability to produce detailed cross-sectional images of the nasal cavity, paranasal sinuses, and brain case without superimposition of other anatomical structures (Hathcock and Stickle 1993, Solano and Brawer 2004, Probst et al. 2005). The paranasal sinuses develop within facial and cranial bones. They communicate with one another and with the nasal cavity. Paranasal sinus surgery is commonly performed in equine practice (Tremaine 2006).

The aim of our work was to describe the anatomy of the nasal and paranasal sinuses of donkey and to produce an anatomic reference for computed tomo- graphy of nasal and paranasal sinuses of donkey for use by radiologists, clinicians and veterinary students.

\section{Materials and Methods}

The anatomy of the donkey's nasal and paranasal sinuses was studied in seven heads and ten skulls using gross anatomy and CT scans. Relevant structures were documented and photographed.

\section{Gross anatomy}

Six donkey's heads ( 4 fresh and 2 formalized) and 10 skulls were used for sagittal sections and anatomical cross sections.

Anatomical cross sections were performed on two donkey's heads (one fresh and one frozen) by using table of a band saw and serial transverse sections were cut approximately $2 \mathrm{~cm}$ apart beginning from the level of the nostrils until the level caudal to temporomandibular joint. Slices were numbered and gently cleaned from debris with water and light brushing and were photographed immediately with the caudal and cranial surfaces of each slice facing the camera. The rest of the specimens were used for sagittal sections.

\section{CT scans}

One donkey's head was used for CT scans after being bled. The head was removed from the level of the third cervical vertebra and CT examination was performed on serially sectioned heads using the CT scanner (CT-W450-10A, HITACHI, Japan). The images taken were from the nostrils until the level caudal tempromandibular joint with 1 cm intervals (scanning conditions: 130 $\mathrm{KV}, 70 \mathrm{MA}$ ). 


\section{Results}

The donkey's head had six pairs of sinuses, three paranasal; the frontal, maxillary and sphenopalatine sinuses and three nasal; dorsal, middle and ventral conchal sinuses.

\section{CT scans of the paranasal sinuses}

(Figs.3, 4, 5) obtained excellent bone window images of the fine bone and soft tissue architecture of the paranasal sinuses and nasal cavity. The relationship between various air cavities was easily visualized. CT images with the most closely corresponding cadaver cross sections were selected. These sections are presented in a rostral to caudal progression from the level of the $2^{\text {nd }}$ premolar tooth to the level of the brain. Both dorsal and ventral nasal conchae have medium density thick wall and spiral form (Figs.3/1\&2), while the conchal sinuses have low density thin wall (Figs.3/5\&6). The maxillary sinus appeared with low density and has high density structures; infraorbital canal, maxillary septum and bony specules (Figs.3/7, 17 \&19). The frontal sinus has low density and contains high-density structures; frontal septum and bony specules (Fig.4/8 \&27). Both sphenopalatine sinuses appeared as rectangular (Figs. 5/6). The following communications between the paranasal sinuses is identified in CT: The conchomaxillary opening connected the ventral conchal sinus with the rostral compartment of the maxillary sinus (Fig.3D \&E, 10). The narrow nasomaxillary opening connected both rostral and caudal maxillary sinuses with the middle nasal meatus (Fig.3C, D \& E, 11). The sphenopalatinal opening communicated the sphenopalatine sinus with the caudal maxillary sinus and the smallest opening which connect the middle conchal sinus with the caudal maxillary sinus (Fig. 2B/35 \&4A/29). The fronto- maxillary opening located on the lateral floor of the frontal sinuses (Fig.3F/12, Fig.4A, 13). The paranasal lining is invisible in CT images because of its thin layer.

\section{Gross anatomy and CT of the para- nasal sinuses:}

\section{1) The Frontal Sinus}

The frontal sinus is air-filled spaces formed by the evagination of the frontal bones into the nasal cavity (Fig.1A/12, Fig.2B , C/1, Fig.5A, B \&D/1). It is triangular in outline with its base medially situated. It is bounded dorsally by frontal bone, ventrolaterally by medial wall of orbit, caudoventerally by cranium and rostroventerally by ethmoturbinates. The sinus continues rostrally with the dorsal conchal sinus forming the conchofrontal sinus (Fig.4A \&C/4) that communicates directly with the caudal maxillary one by a large, oval or beanshaped frontomaxillary opening. This opening is about 4-5 cm length and 2.5$3.5 \mathrm{~cm}$ width (Fig.1A,C/15, Fig.3,F,L/12, Fig.4A,C/13), and is located in a dorsal plane slightly caudal to medial canthus of the eye. The frontomaxillary opening is at the level of the caudal third of second molar tooth (Fig.3B/19) and extended $2-3 \mathrm{~cm}$ caudal to the last molar tooth on the lateral floor of the conchofrontal sinus(Fig.3F,L/12). The left and right frontal sinuses are completely separated by a thick midline bony septum (Fig.1A, C/13, Fig.3F,L/4, Fig.4B \&C/8). There is a convexity existed on the floor of the frontal sinus due to the presence of the underlying ethmoidal labyrinth (Fig.4B \&C/3) and the cavity appears irregular due to the presence of several bony specules

\section{1. a. Topography of frontal sinuses}

The sinus extended caudally to a line rostral to the temporomandibular joint 
and passing on the level of the caudal border of supraorbital process (Fig.1A). Rostrally, the conchal part of the frontal sinuses extended to the point of the nasal bones divergence towards the orbit, rostral to the nasofrontal suture. The topographical limits of frontal sinus were determined by a line indicated the lateral limit of sinus from the nasoincisive notch to the base of the ear passing through the medial angle of the eye and the supraorbital foramen. Actually a line, $18-20 \mathrm{~cm}$ in length starts from the caudal border of the supraorbital process until the nasoincisive notch (Fig.1A/A). On the other hand, a line approximately through the midline of the head was the medial limit of sinus (Fig.1A/B). The caudal limit of sinus was determined by transverse line, about 5-6 cm long, passing through the middle of the zygomatic arch from the caudal border of the supraorbital process to the midline of head (Fig.1A/C). The rostral limit of the sinus was indicated by a line, about $3-4 \mathrm{~cm}$ long, passes through the halfway distance between the medial angle of the eye and the end of the facial crest (Fig.1A/D). The widest part of frontal sinus lies midway between the supraorbital foramen and the medial canthus of the eye.

\section{1. b. Clinical Importance}

A surgical frontonasal flap recommended to approach the interior of the frontal sinus is at an area between the two lines, the caudal line passing midway between the supraorbital foramen and the medial canthus of the eye to a point about $1.5 \mathrm{~cm}$ away from the medial aspect of the orbital rim toward the midline (Fig.1E/24). The rostral line is parallel to the caudal line and $1.5-2 \mathrm{~cm}$ caudal to where the nasal bone begins to diverge (Fig.1E/25) or rostral to the medial canthus by $4 \mathrm{~cm}$, this line extends laterally from the midline to an imaginary line drawn between the medial canthus of the eye and the nasoincisive notch. Then connected the lateral extent of the caudal and rostral lines by lateral segment (Fig.1 D /31), to create the flap, a three-sided, rectangular with slightly rounded corners. The approach should avoid crossing the nasolacrimal duct, which coursed between the medial canthus of the eye and the nasoincisive notch.

\section{The maxillary sinuses}

The maxillary sinuses were air-filled spaces formed by the evagination of the maxillary, lacrimal and zygomatic bones and communicated directly with the nasal cavity. They were divided into rostral and caudal compartments by a thin incomplete bony septum (Fig.1B\&D/18\&3F\&l/17), the dorsal part of the septum is formed by the bulla of the ventral conchal sinus (Fig.2A\&B/25, Fig.3I/18). This septum angled obliquely caudally and its rostral aspect can vary in position, usually across the roots of the second and third molar teeth, approximately $4-5 \mathrm{~cm}$ caudal to the rostral end of the facial crest. In the present study, most of the cases have a low septum of about $1.5 \mathrm{~cm}$ high. Only in one case, the septum was $3 \mathrm{~cm}$ high and was absence in three other cases. The depth of the sinus in animals over 8 years of age was about $4-5.5 \mathrm{~cm}$, while at 5 years was about $2.5-3.5 \mathrm{~cm}$. There are bony specules (Fig.3H/19\&4 A/27) which subdivided the cavity of rostral and caudal parts of the maxillary sinus into several loculea.

The caudal maxillary sinus was partially divided into medial (Fig.1B/17, Fig.2B/28') and lateral (Fig.1B\&C/14, Fig.2 B/28, Fig.3F \& L/9) compartments by the infraorbital canal (Fig.2B $/ 31 \& 3 F / 7$ ) that run longitudinally through 
the maxillary sinuses. These two parts being in free communication over the canal. The lateral roots of the last premolar and $1^{\text {st }}$ molar were embedded in the rostral maxillary sinus in the 5-year old donkeys, while the roots of the $2^{\text {nd }}$ and $3^{\text {rd }}$ maxillary molars were embedded in the caudal maxillary sinus. Up to 8-years old donkeys, the maxillary sinus increases in size and extends to the level of the rostral root of the last premolar. The last premolar and $1^{\text {st }}$ and $2^{\text {nd }}$ molars were embedded in the rostral maxillary sinus, while the roots of the $3^{\text {rd }}$ (Fig.2B/41) maxillary molar tooth were embedded in the caudal maxillary sinus. By the advance in age, the premolars roots become separated from maxillary sinus by a thin plate of bone (Fig.1 D /33).

Both rostral and caudal maxillary sinuses are connected with the middle nasal meatus via a slit-like nasomaxillary opening (Fig.1B/21, Fig.2A / 27 \& 3D \& $E / I I)$ which is the narrowest communicating opening located at the level from middle of $1^{\text {st }}$ molar tooth to rostral third of the $3^{\text {rd }}$ molar tooth. The opening measured 3.5-4 cm length and 0.1-0.2 $\mathrm{cm}$ width. The caudal maxillary sinus is communicated with the sphenopalatine and middle conchal sinuses.

The rostral maxillary sinus is smaller than the capacious caudal maxillary sinus. It is communicated with the ventral conchal sinus via the wide conchomaxillary opening (Fig. 1B/22, Fig.2B/26 \& Fig.3D, E, K/10), dorsal to the infraorbital canal (Fig.1B/20, Fig.3D, E, K/7). The opening lies at the level of the rostral part of first molar to caudal part of the $2^{\text {nd }}$ molar tooth. It measured about $4.4-5 \mathrm{~cm}$ length and $0.3-0.4 \mathrm{~cm}$ width.

\section{2. a. Topography of maxillary sinus- es}

The dorsal margin of the maxillary sinus was clinically described by an imaginary line joining a point, about $4 \mathrm{~cm}$, caudal to the medial canthus of the eye, to the nasoincisive notch (Fig.1B/E). The rostral border of the maxillary sinus lies at the level of the third premolar tooth and is represented by a vertical line which go through a point located about $1.5 \mathrm{~cm}$ rostral to the lower end of the facial crest (Fig.1B/G). Caudally the sinus was determined by a vertical line through the supraorbital process (Fig.1B/H), indicating that the cavity extended for about $4 \mathrm{~cm}$ below the orbit. The ventral margin of the sinus was about $1-1.5 \mathrm{~cm}$ ventral to the facial crest (Fig.1B/F), where the facial crest was not the ventral limit of the sinus but it is considered the ventral practical limit.

\section{2. b. Clinical importance}

The approach to the interior of the caudal maxillary sinus (Fig.1F/28) is at area above the level of the facial crest by about $1 \mathrm{~cm}$, about $1.5 \mathrm{~cm}$ rostral to orbit and about $1 \mathrm{~cm}$ ventral to the nasoincisive notch medial canthus of the eye line that considered the course of the nasolacrimal duct.

Approach to the interior of the rostral maxillary sinus (Fig.1F /29) is at area about $1.5 \mathrm{~cm}$ upward from the facial crest toward the midline and $1.5 \mathrm{~cm}$ from the rostral end of the facial crest (Fig.1E/8). Standard diagnostic techniques are appropriate; although with the shorter length of the facial crest, about $10 \mathrm{~cm}$, it was appropriate to use a small trephine opening $(1-1.5 \mathrm{~cm})$ for access to the rostral and caudal maxillary sinuses.

\section{The sphenopalatine sinuses}

The sphenopalatine sinuses were excavated in the palatine and sphenoid 
bones ventromedial to the orbit and ventral to forebrain (Fig.2C/5, Fig.4B/28 \& $5 A, B, C, E \& F / 6)$. The septum dividing the left and right sphenoidal sinuses was found in all cases, however, not frequently in the midline (Fig.5C\& F/7). The sphenoidal and palatine sinuses are communicated to each other. The dorsal and lateral walls of the sphenopalatine sinus are thin. It is communicated with the caudal maxillary sinus via the sphenopalatinal opening, which is the most caudal opening of the maxillary sinus; the opening appeared sagittal oblique located between the caudal origin of the infraorbital canal and the pterygopalatine fossa caudal to the roots of the last molar tooth. It measured 1.5 to $2 \mathrm{~cm}$ in length and 0.8 to 1 $\mathrm{cm}$ in width (Fig. 4A \& B/23).

\section{Gross anatomy and CT of the nasal sinuses:}

The dorsal, middle and ventral conchal sinuses are enclosed within the nasal conchae.

The dorsal conchal sinuses are enclosed within the caudal portion of the dorsal nasal concha and are laid rostromedial to the orbit. It extends from the level of the caudal third of $1^{\text {st }}$ molar to $3^{\text {rd }}$ molar teeth. The rostral portion of the dorsal nasal concha was the scrolls, surrounding recesses of the nasal cavity (Fig.1C/30, Fig.2A/2 \& Fig. 3E, F, L/5).

The middle conchal sinuses are enclosed within the middle nasal concha. The latter is located between the ethmoidal labyrinth and dorsal nasal sinus and appeared oval in C.T (Fig 2C/4 \& Fig $4 A$ \& B /6). It is connected with the caudal maxillary sinus by small oval opening measuring $0.4 \mathrm{~cm}$ long and $0.2 \mathrm{~cm}$ wide (Fig 2B/35 \& 4A/29).
The ventral conchal sinuses (Fig $2 \mathrm{C} / 3$ \& Fig 3D, H/6)) are enclosed within the caudal portion of the ventral nasal concha (Fig.2D/14, Fig.3D, G, H/28). The rostral portion of ventral nasal concha forms scrolls surrounding recesses. It extended from the level of the $1^{\mathrm{ST}}$ molar to the rostral part of $3^{\text {rd }}$ molar tooth. The ventral conchal sinuses form the medial compartment of the rostral maxillary sinus. The ventral conchal sinuses drain dorsally over the infraorbital canal into the rostral aspect of the rostral maxillary sinus via a narrow conchomaxillary opening. The caudal portion of the ventral conchal sinus formed the bulla of the ventral nasal concha.

\section{Discussion}

The current work on paranasal sinuses could be used as a reference aid in CT imaging diagnosis of donkey's head disorders and in understanding the complex anatomy of paranasal sinuses of donkeys. The nasal cavity and paranasal sinuses have good image contrast in CT because of the adjacent air and bone, a bone window is necessary to differentiate bone from mucous membranes. On the other hand, in a soft-tissue window, bone and mucosa will appear as a homogeneous area, whereas the real thickness of each structure will be masked this is in a line with that recorded by Morrow et al. (2000) in horse. CT is superior for transverse imaging the equine skull that allows proper three-dimensional orientation and extension, location, and size of pathologies this is in a line with that recorded by Henninger et al. (2003) and Probst et al. (2005) in horse. The communications between the paranasal sinuses were detectable in CT and gross anatomy; however, the number, description, definition, and nomenclature of the openings are different in various anatomic papers and textbooks 
Nickel et al. (1973), Kainer (1993), Morrow et al. (2000) and Probst et al. (2005) in horse. The lining of the paranasal sinuses was invisible in CT images of donkeys head; this was similar to that recorded by Probst et al. (2005) in horse.

Frontal sinus was triangular in shape united rostrally with the dorsal conchal sinus forming conchofrontal sinus, similar to that described by Nickel et al. (1973) in horse .A surgical frontonasal flap recommended to approach to the interior of the frontal sinus, created over the conchofrontal sinus in a manner similar to that described by Schumacher and Perkins (2005) in horse. Moreover, through a frontonasal flap we can explore of the frontal, maxillary and the ventral conchal sinuses

In our study the maxillary sinus had incomplete bony septum which varied in its position and height. Omar et al. (1985) in donkey reported its absence in the same animal species. On the contrary, it has complete septum in horse (Budras et al., 2001, Tremaine and Dixon, 2002 and Probst et al., 2005). In the present investigation, it was observed that the roots of the $2^{\text {nd }}$ and $3^{\text {rd }}$ maxillary molar teeth were embedded in the caudal maxillary sinus in a 5-year old donkey, while up to 8 years old the third maxillary molar tooth was embedded in the caudal maxillary sinus, this was similar to that stated by Amin and Kassem (1987) in donkey. Surgical approach to the frontal and maxillary sinuses provided a good debridement of the sinuses, in addition to the maxillary sinus approach considered the best way for repulsion of the $3^{\text {rd }}$ maxillary molar tooth because the oral extraction of the $3^{\text {rd }}$ maxillary molar tooth was difficult due to the exposed crown has low profile and the space between molar teeth was limited and its root resided within the caudal maxillary sinus, this is in agreement with the previously recorded by Boutros and Koenig (2001) in horse.

The maxillary sinus approach in donkeys faced two problems; the first problem was the short length of the facial crest (about $10 \mathrm{~cm}$ ), which needed a small trephine $(1-1.5 \mathrm{~cm})$ to access the rostral and caudal maxillary sinuses. These results were in the same line of that stated by Nouh (1991) and Makady (1992) in donkey, Thiemann, and Bell (2001) in horse. The second problem was the infraorbital canal that run longitudinally through the caudal maxillary sinus and divided it into medial and lateral compartments, so to avoid the fracture of this canal the trephine should be about $1 \mathrm{~cm}$ ventral to the nasoincisive notch and at the medial canthus of the eye. This is in a line with that recorded by Tremaine and Dixon (2002) in horse. Omer et al. (1985) described the site of trephining in the maxillary sinus by intersection of two imaginary lines, the first line connects the lacrimal tubercle and rostral end of facial crest and the second line runs between lateral canthus of eye and the infraorbital foramen. We suggested two sites for trephining the maxillary sinus (in its rostral and caudal parts) instead of one, even with absence of the septum in the maxillary sinus due to its caudal extension under the orbit and the presence of bony plates and specules.

\section{References}

Amin, M.E. and Kassem, M.M. (1987):Topographical anatomical studies on the teeth with special reference to some surgical affections in donkey and horse. Assuit Vet. Med . J. 18, 35:212-222. 
Barbee, D. D., J. R. Allen, and

Gavin, P. R. (1987): Computed tomography in horses: technique. Veterinary Radiology \& Ultrasound. 28, 144-151.

Boutros, C. P. and Koenig, J.B. (2001): A combined frontal and maxillary sinus approach for repulsion of the third maxillary molar in a horse. Can Vet J.42: 286-288.

Budras, K.D., Sack, W. O. and

Rock, S. (2001): Anatomy of the horse - An illustrated text, 3rd edition. Schlutersche $\mathrm{GmbH}$ \& Co. KG, Verlag und Druckerei. Hannover. Pp:30.

Gibbs, C. (1999): Dental imag ing. In Baker GJ, Easley J (eds): Equine Dentistry, Philadelphia, WB Saunders, Pp 139169.

Hathcock, J.T. and Stickle, R.L. (1993): Principles and concepts of computed tomography. Vet Clin North Am Small Anim Pract 23:399-415.

Henninger, W., Frame, E. M., Willmann, M., Simhofer, H., Malleczek, D., Kneissl, S. M. and Mayrhofer. E. (2003): CT features of alveolitis and sinusitis in horses. Veterinary Radiology \& Ultrasound.44(3): 269276.

Kainer, R. A. (1993): Clinical anatomy of the equine head. Vet Clin North Am Equine Pract. 9(1):1-23.

Makady, F.M. (1992): Chronic primary sinusitis of the ventral conchal sinus in donkey. Assiut Vet Med J. 27(53):249-254.

Morrow, K.L., Park, R.D.,

Spurgeon, T.L., Stashak, T.S. and Arceneaux, B. (2000): Computed tomographic imaging of the equine head. Veterinary
Radiology \& Ultrasound. 41(6):491-7.

Nickel R.; Schummer A. and Sei

ferle, E. (1973): The viscera of domestic mammals. translation and revesion by W.O. Sack. Verlag Paul parey Berlin. Humburg.

Nouh, S.R. (1991): Unusual seat for a fibrosarcoma along the paranasal sinuses in a donkey. Assuit Vet Med J. 25(49):268271.

Omar, A, I. Khdr, A.Kamel, M.

Abdel-Maaboud and.ElSeddawy, F. (1985): Surgical and anatomical studies of the paranasal sinuses of the donkey. The Ninth Scientific Conference of the Egyptian society of histology and cytology. Held at faculty of Medicine Al-Azhar University in 26 Dec. (Acceptance).

Probst, A., Henninger, W. and

Willmann, M. (2005): Communications of normal nasal and paranasal cavities in computed tomography of horses. Veterinary Radiology \& Ultrasound. 46(1):44-48.

Schumacher, J. and Perkins, J. (2005). Surgery of the Paranasal Sinuses Performed with the Horse Standing.Clin TechEquine Pract. 4:188-194.

Solano, M. and Brawer, R. S. (2004): CT of the Equine Head: Technical Considerations,Anatomical Guide , and Selected Diseases Clin Tech Equine Pract. 3:374-388.

Starkey, P. (1997): The Professional Handbook of the Donkey. In: Svendsen ED ed. London: Whittet Books Ltd 3rd ed.183184.

Thiemann, A.K. and Bell, N. J. 
(2001): The Peculiarities of Donkey Respiratory Disease.

In: Equine Respiratory Diseases, P. Lekeux (Ed.) Publisher: International Veterinary Information Service (www. ivis.org), Ithaca, New York, USA.

Tremaine, W. H. and Dixon, P.

M. (2002): Diseases of the Nasal Cavities and Paranasal Sinuses In: Equine Respiratory Diseases, P. Lekeux (Ed.) Publisher: International Veterinary Information Service (www. ivis.org), Ithaca, New York, USA.

Tremaine, W. H. (2006) :Compli- cations Associated with Dental and Paranasal Sinus Surgery. American Association of Equine Pra-ctitioners - AAEP-Focus Meeting, 2006 -Indiana-polis, IN, USA.

This manuscript is reproduced in the IVIS website with the permission of AAEP www.aaep.org. 

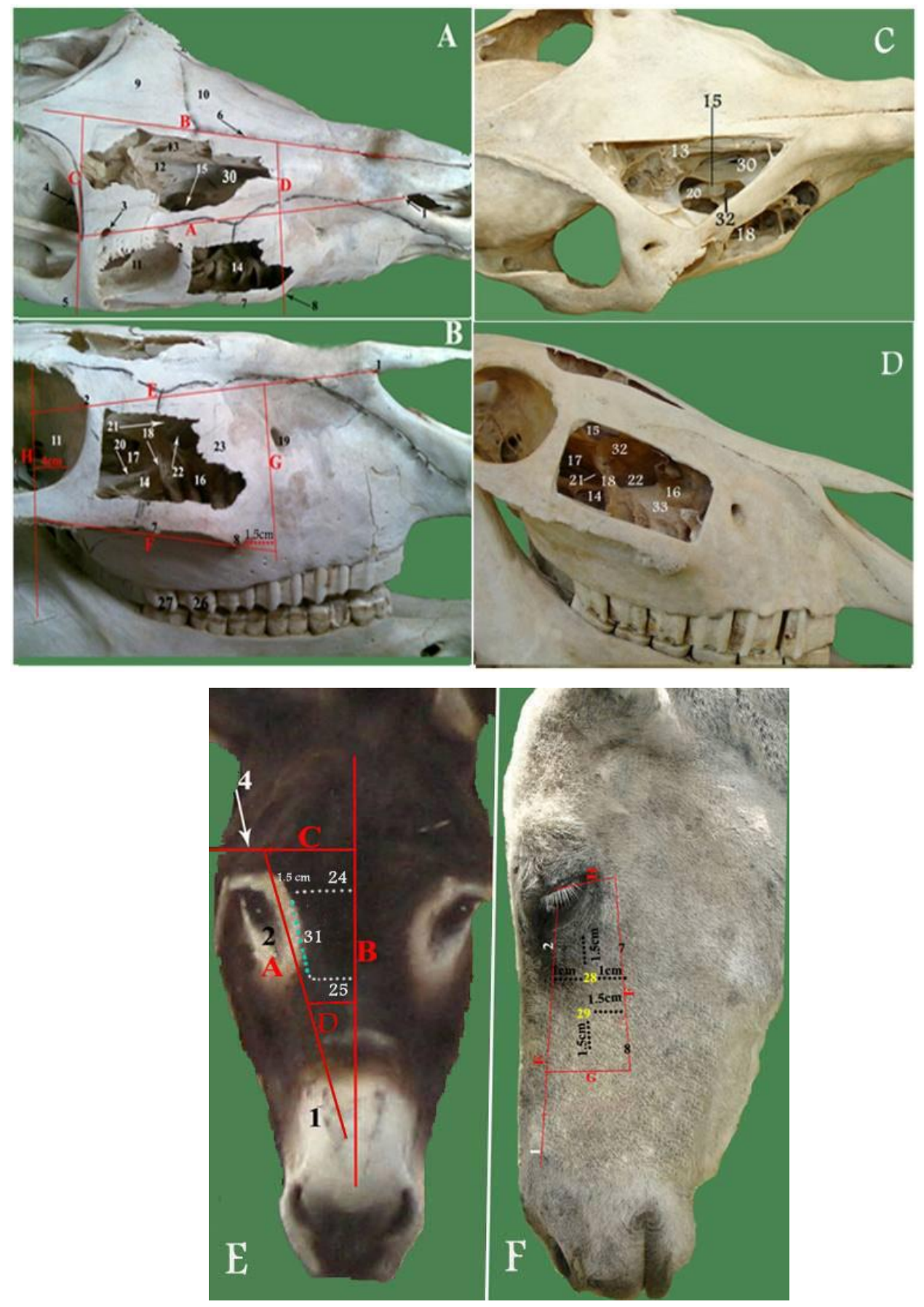

J. Vet. Anat. 
Nasal and paranasal sinuses in the donkey

El-Gendy and Alsafy

Fig (1): Topography of frontal and maxillary sinuses of the donkey skulls (A, B, 5 years, C\&D 12 years) and head of donkey (E\& F).

1 , nasoincisive notch; 2 , medial angle of the eye; 3 , supraorbital foramen; 4 , caudal border of supraorbital process; 5 , zygomatic arch; 6 , midline of skull; 7 , facial crest; 8 , the end of facial crest; 9 , frontal bone; 10 , nasal bone; 11 , orbit; 12 ,frontal sinus; 13 , frontal septum between right and left frontal sinuses; 14 , lateral compartment of caudal maxillary sinus; 15 , frontomaxillary opening; 16 , rostral maxillary sinus; 17 , medial compartment of caudal maxillary sinus; 18 , maxillary septum between rostral and caudal maxillary sinuses; 19, infraorbital foramen; 20, infraorbital canal; 21 , nasomaxillary opening; 22, conchomaxillary opening; 23 , maxillary bone; 24 , dotted line indicated the caudal approach line of conchofrontal sinus; 25 , dotted line indicated the rostral approach line of conchofrontal sinus; $26,2^{\text {nd }}$ maxillary molar tooth; $27,3^{\text {rd }}$ maxillary molar tooth; 28 , site of approach of caudal maxillary sinus; 29 , site of approach of rostral maxillary sinus; 30 ,dorsal conchal sinus; 31 , the lateral segment connected the lateral extent of the caudal and rostral lines; 32, bulla of ventral nasal conchal sinus(opened); 33, bony plate; A, lateral limit of frontal sinus; B, medial limit of frontal sinus; $C$, caudal limit of frontal sinus; $D$, rostral limit of frontal sinus; $E$, dorsal limit of maxillary sinus; F, ventral limit of maxillary sinus; $G$, rostral limit of maxillary sinus; $\mathrm{H}$, caudal limit of maxillary sinus. 

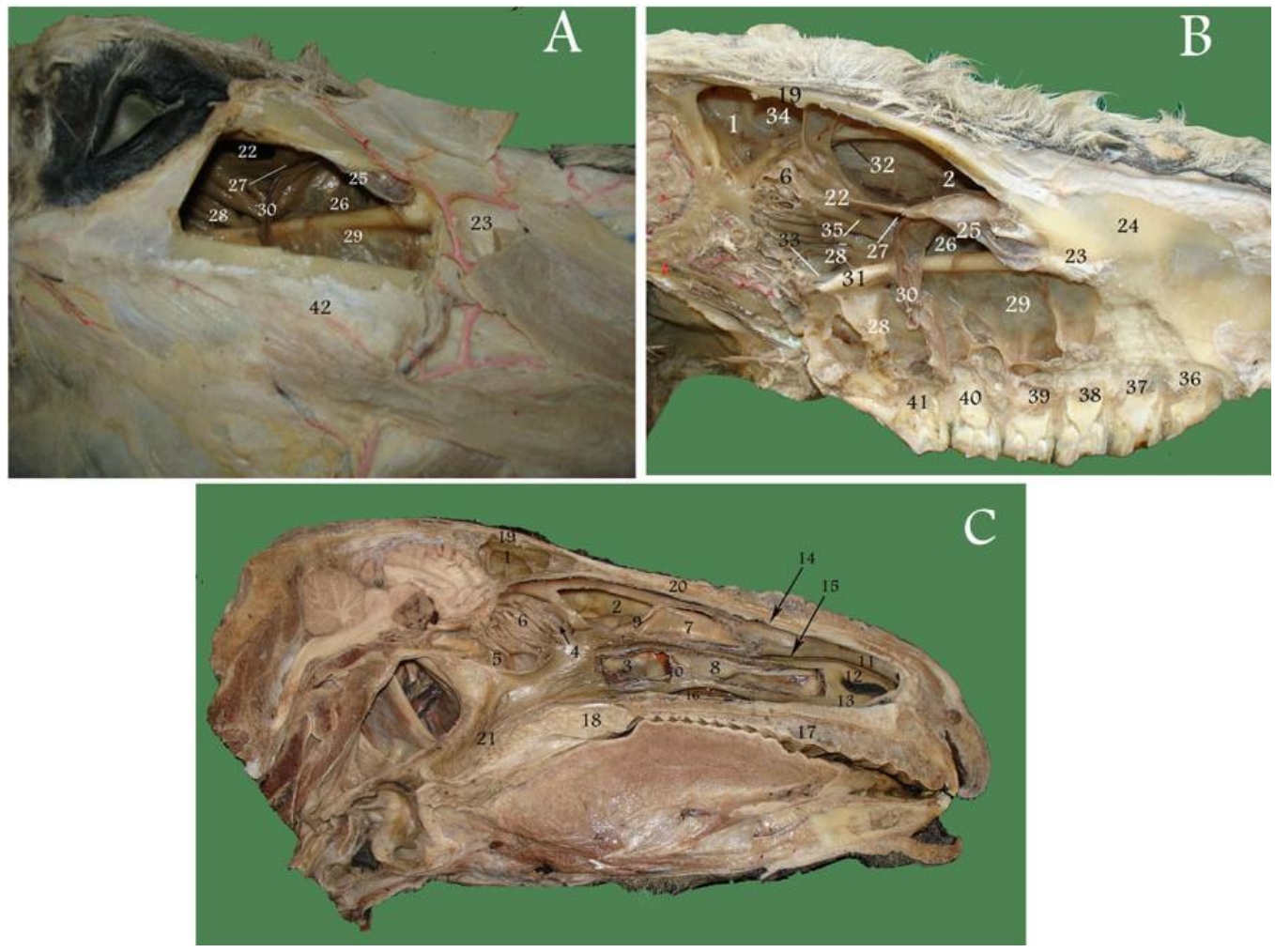

Fig (2): Sagittal sections (A, B 12 years \&C 8 years) of the head of the donkeys.

1, frontal sinus; 2 , dorsal conchal sinus; 3 , ventral conchal sinus; 4 , middle conchal sinus; 5 , sphenopalatine sinus; 6 , ethmoidal turbinate; 7 , bulla of the dorsal nasal concha; 8 , bulla of the ventral nasal concha; 9 , septum of ventral nasal concha; 10 , septum of dorsal nasal concha; 11 , straight fold; 12 , alar fold; 13 , basal fold;14, dorsal nasal meatus; 15,middle nasal meatus; 16 , ventral nasal meatus; 17 , hard palate; 18, soft palate; 19, frontal bone; 20 , nasal bone; 21 ,pharynx; 22 ,frontomaxillary opening; 23 , infraorbital nerve; 24 , maxillary bone; 25 ,bulla of ventral nasal conchal sinus; 26 , conchomaxillary opening; 27 , nasomaxillary opening; 28 , lateral part of caudal maxillary sinus; 28', medial part of caudal maxillary sinus; 29 , rostral maxillary sinus; 30 , maxillary septum;31, infraorbital canal; 32,nasolacrimal duct; 33,sphenopalatine opening; 34, frontal septum; 35 , opening of middle nasal conchal sinus into caudal maxillary sinus; $36,1^{\text {st }}$ maxillary premolar tooth; $37,2^{\text {nd }}$ maxillary premolar; $38,3^{\text {rd }}$ maxillary premolar; $39,1^{\text {st }}$ maxillary molar tooth; $40,2^{\text {nd }}$ maxillary molar tooth; $41,3^{\text {rd }}$ maxillary molar tooth; 42 , facial crest. 

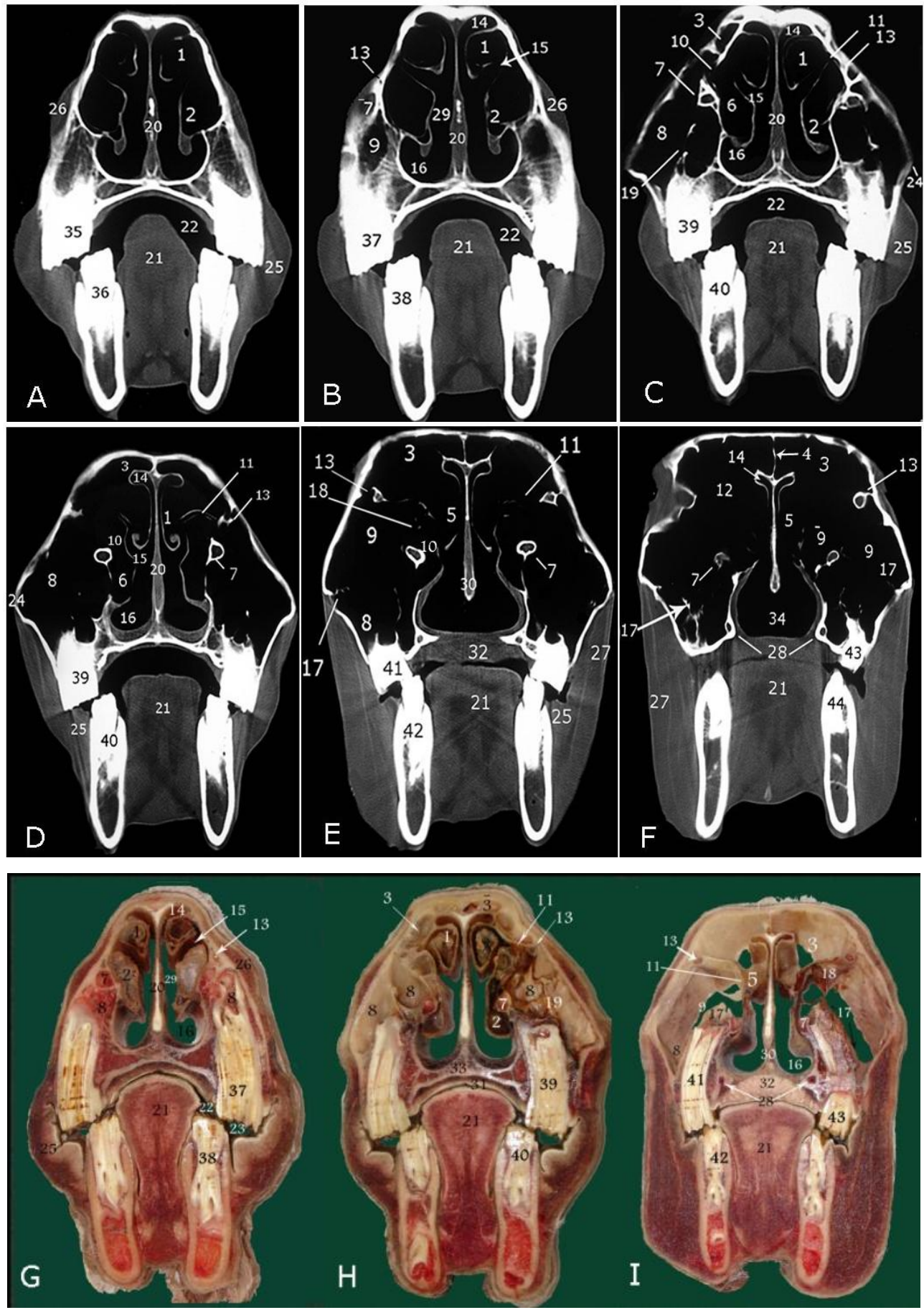


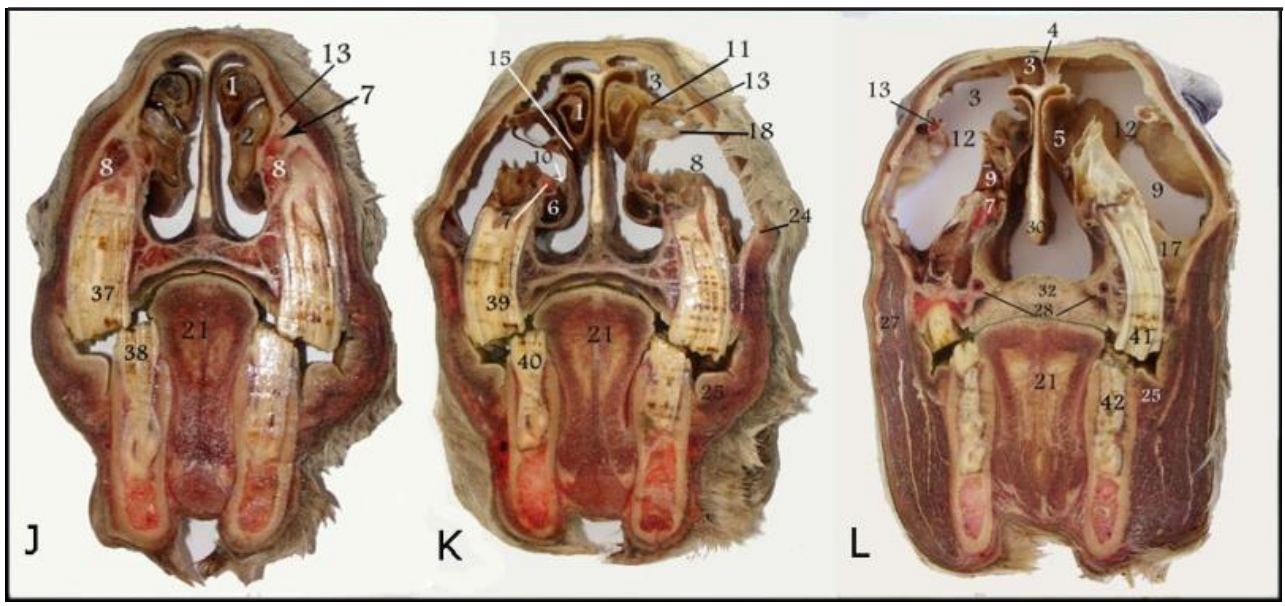

Fig (3): CT images (A-F) and cross sections (G, H\&l caudal view and J, K\&L cranial view) at the level of the frontal, maxillary and conchal sinuses.

1, dorsal nasal concha; 2 , ventral nasal concha; 3 , conchofrontal sinus; $3^{\prime}$, frontal sinus; 4 , frontal septum between right and left frontal sinuses; 5 ,dorsal conchal sinus; 6 ,ventral conchal sinus; 7 , infraorbital canal; $7^{\prime}$, infraorbital foramen ; 8 , rostral maxillary sinus; 9 , lateral part of caudal maxillary sinus; $9^{\prime}$, medial part of caudal maxillary sinus; 10 , conchomaxillary opening; 11 , nasomaxillary opening; 12, frontomaxillary opening; 13, lacrimal canal and nasolacrimal duct; 14, dorsal nasal meatus; 15 , ventral nasal meatus; 16 , , ventral nasal meatus ; 17 , maxillary septum between rostral and caudal maxillary sinuses; 18 ,bulla of ventral nasal conchal sinus ; 19,bony specules and plates; 20 , nasal septum; 21 , tongue; 22 ,oral cavity proper; 23 , oral vestibule; 24 , facial crest; 25,buccinator muscle; 26,superior labii levator muscle; 27 ,masseter muscle; 28 ,palatine canal;29, common nasal meatus; 30 , vomer bone within nasal septum; 31 , hard palate; 32,soft palate; 33 , palatine process of maxilla; 34 , nasopharynx; $35,2^{\text {nd }}$ maxillary premolar teeth; $36,2^{\text {nd }}$ mandibular premolar teeth; $37,3^{\text {rd }}$ maxillary premolar teeth; $38,3^{\text {rd }}$ mandibular premolar teeth; $39,1^{\text {st }}$ maxillary molar teeth; $40,1^{\text {st }}$ mandibular molar teeth; $41,2^{\text {nd }}$ maxillary molar teeth; $42,2^{\text {nd }}$ mandibular molar teeth; $43,3^{\text {rd }}$ maxillary molar teeth; $44,3^{\text {rd }}$ mandibular molar teeth. 

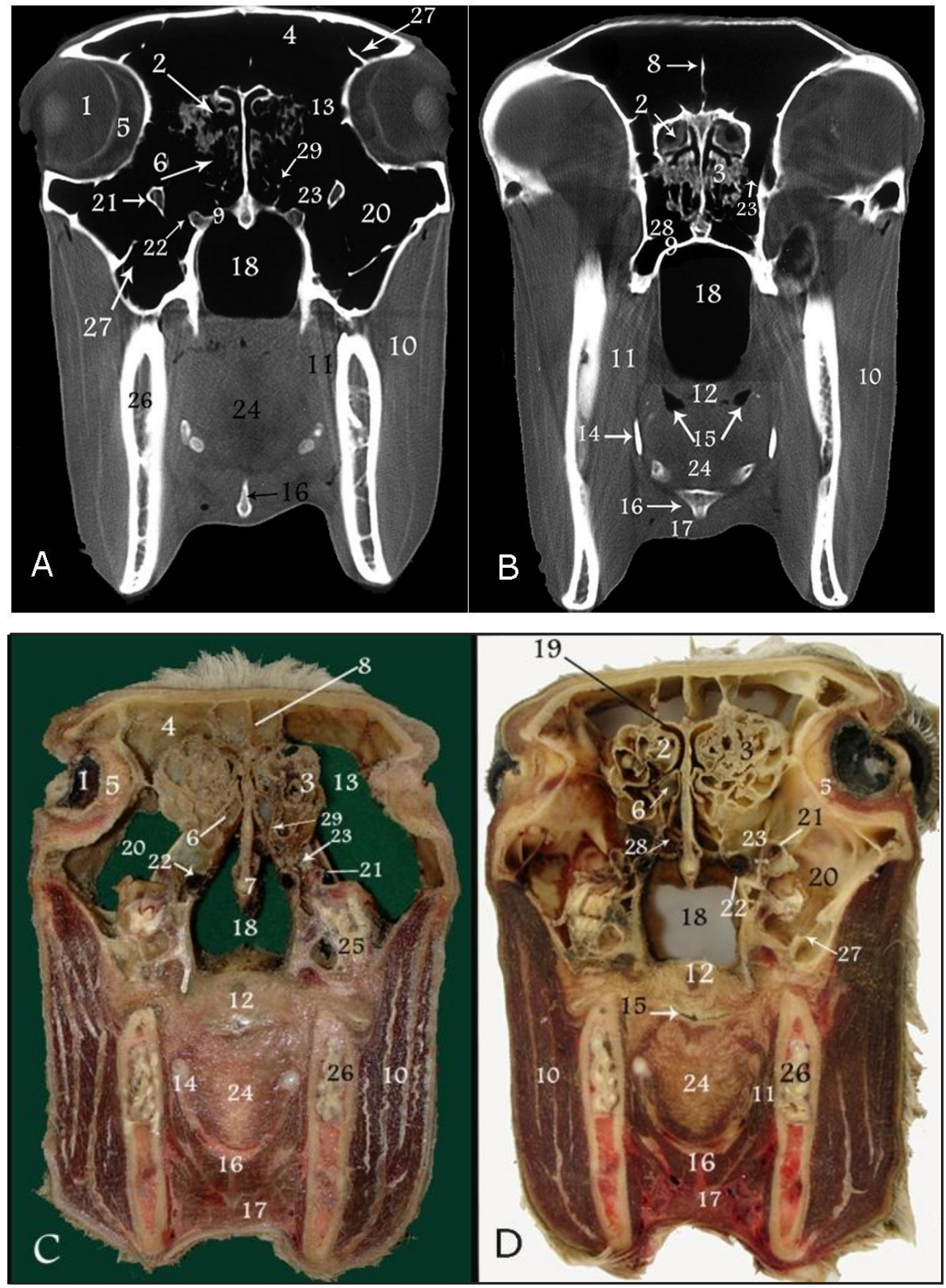


\section{Fig (4): CT images (A \& B) and cross sections (C caudal view \& D cranial view) at} the level of the ethmoidal labyrinth.

1, eye (choroid and retina); 2, dorsal conchal sinus; 3 ethmoidal labyrinth; 4 , conchofrontal sinus; 5 , periorbital fat and ocular muscles; 6 , middle conchal sinus; 7 , vomer bone; 8 , Frontal septum between right and left frontal sinus; 9 , palatine bone; 10, masseter muscle; 11 ,medial pterygoid muscle; 12 , soft palate; 13 , frontomaxillary opening; 14 , stylohyoid bone; 15 , oropharynx; 16 , basihyoid bone; 17, omohyoid and sternohyoid muscles; 18, nasopharynx; 19, dorsal nasal meatus; 20 , caudal maxillary sinus; 21 , Infraorbital canal; 22, sphenopalatine vessels; 23 , sphenopalatinal opening; 24 , root of tongue; $25,3^{\text {rd }}$ maxillary molar teeth; $26,3^{\text {rd }}$ mandibular molar teeth; 27 ,boney specules; 28 , sphenopalatine sinus; 29 , opening of middle conchal sinus into caudal maxillary sinus.
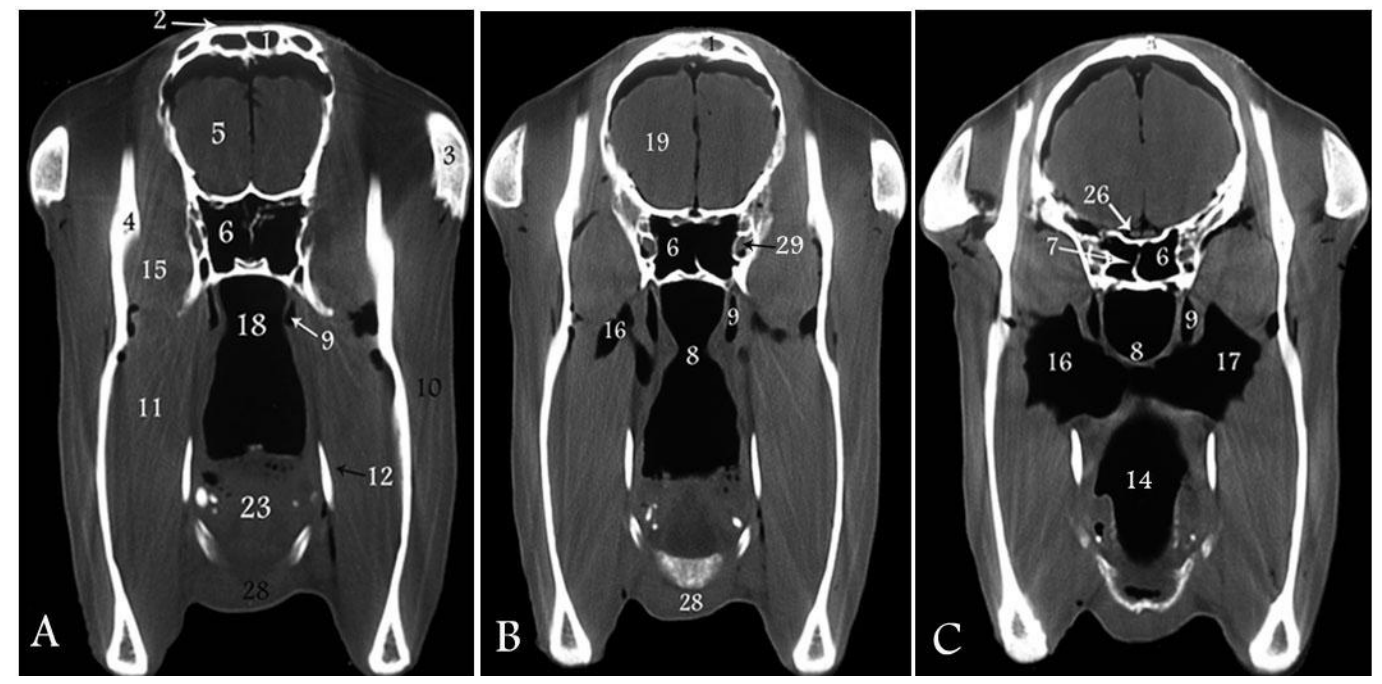


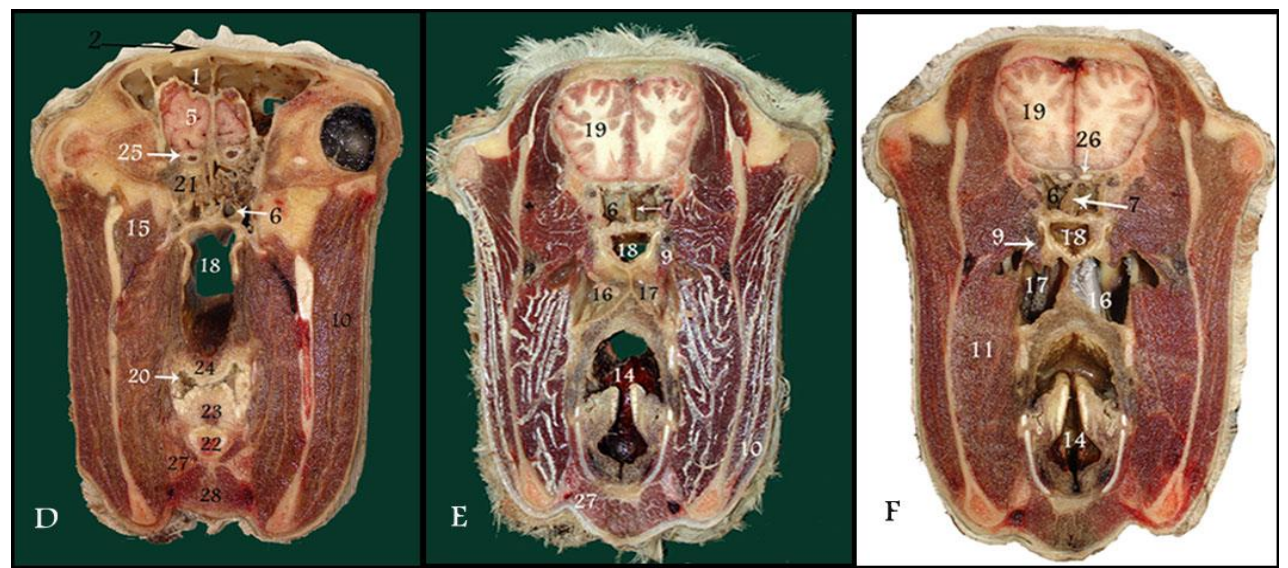

Fig (5): CT images (A, B \& CS) and cross sections (D, E caudal view \& F cranial view) at the level of the frontal and sphenopalatine sinuses.

1, frontal sinus; 2 , frontal bone; 3 , zygomatic process of temporal bone; 4 , coronoid process of the mandible; 5 , frontal lobe of brain; 6 , sphenopalatine sinus; 7 , sphenopalatine septum; 8 , pharynx; 9 , auditory tube; 10 , masseter muscle; 11 , medial pterygoid muscle; 12 , stylohyoid bone; 13 , thyrohyoid bone; 14, larynx; 15, lateral pterygoid muscle; 16,left guttural pouch;17,right guttural pouch; 18, nasopharynx; 19, cerebral hemisphere; 20,oropharynx; 21,ethmoid labyrinth; 22, basihyoid bone; 23,root of tongue and epiglottis apex; 24, soft palate; 25,olfactory bulb; 26,optic nerve; 27; mandibular salivary gland; 28 , omohyoid and sternohyoid muscles; 29, alar canal. 